\title{
Light Scattering
}

National Cancer Institute

\section{Source}

National Cancer Institute. Light Scattering. NCI Thesaurus. Code C62323.

Dispersal of a beam of light into a range of directions as a result of physical interactions. 